\title{
Urmila Pawar on Empowerment of Dalit Women and the Aesthetics of Dalit Feminist Identity: A Personal Interview
}

\author{
Munira Salim \\ Lecturer and Head, Department of English, Stewart Science College, Cuttack, Odisha \& \\ PhD Scholar, Ravenshaw University, Cuttack.Email: munirasalim23@gmail.com
}

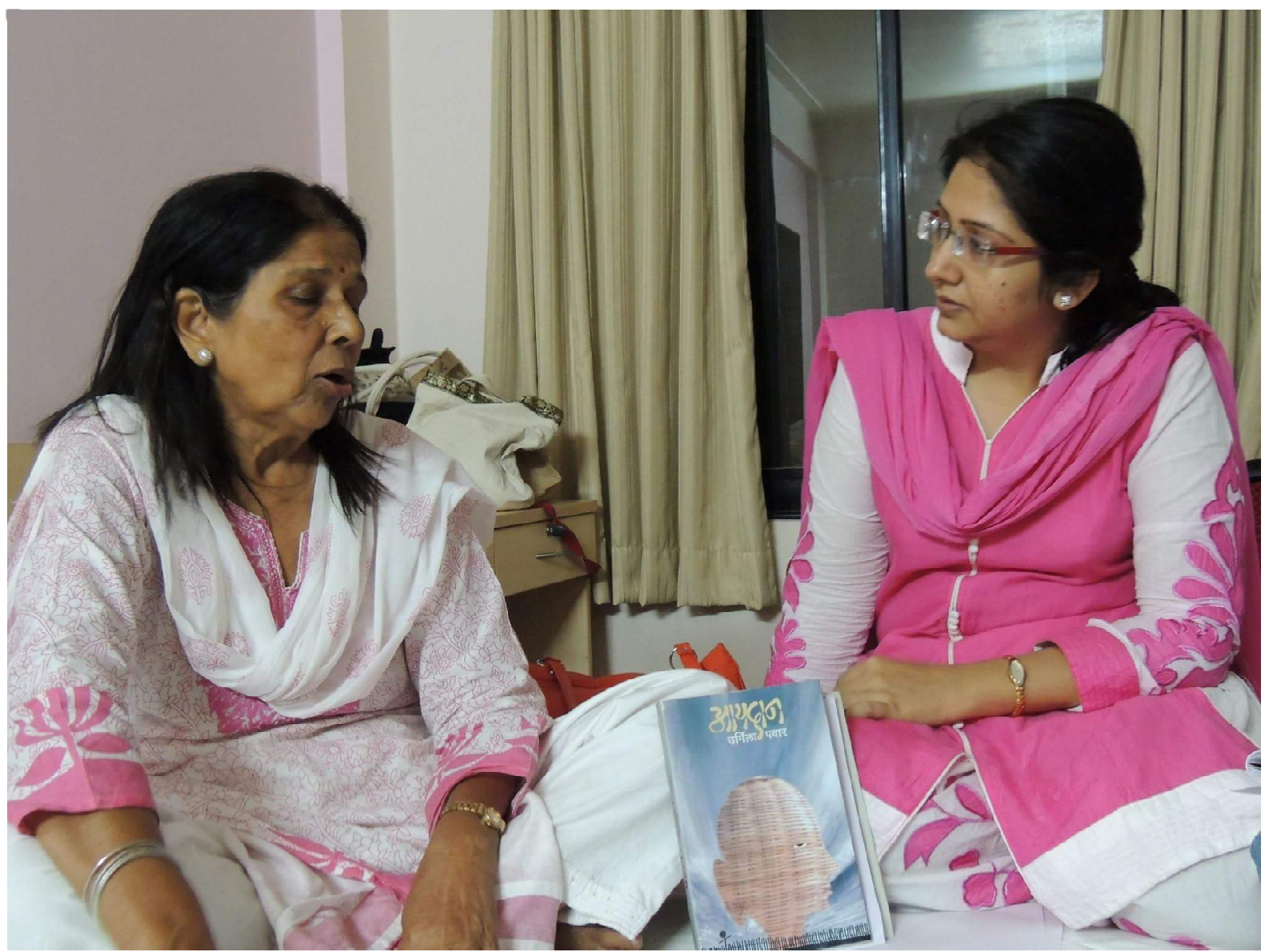

\section{Introduction}

A desperate wish to meet few literary luminaries made me attend the AHRC funded International Conference in the University of Pune that was held in December, 2015. It was the peak of winter though the city was experiencing moderate climate, and naturally, it was quite comfortable to cope up with the winter's warmth! One of my wishes that I had nurtured for long was to meet the Dalit feminist writer Urmila Pawar. As the Conference brochure revealed her presence, I started (C) AesthetixMS 2016. This Open Access article is published under a Creative Commons Attribution Non-Commercial 4.0 International License (http://creativecommons.org/licenses/by-nc/4.o/), which permits non-commercial re-use, distribution, and reproduction in any medium, provided the original work is properly cited. For citation use the DOI. For commercial re-use, please contact aesthetixms@gmail.com. 
feeling restless, though I was uncertain about the success of my plan. But I was in for a surprise! On the first day of the Conference, Urmila was sitting just two rows ahead of mine, and I was taken aback. For me, the writers of her kind are like the twinkling stars in the Milky Way and I was happy that I had travelled the distance to meet my star! Anyway, after a formal introduction I proposed for an interview which she affirmed to my happiness!

\section{A Note on the Author:}

Urmila Pawar is a dalit feminist writer and an activist hailing from Maharashtra. As a dalit writer she has placed herself among other eminent writers like Sharankumar Limbale, Daya Pawar and Baby Kamble. In the contemporary period, she is one of the most prominent figures in Dalit Literature. She is much acclaimed for her short stories and also as a dalit feminist historian. In her documentation We Also Made History: Women in the Ambedkarite Movement, with Meenakshi Moon (1989), she gives a detailed account of the participation of women in the dalit movement led by Dr B.R. Ambedkar. Her life narrative, originally written in Marathi as Aayadan in 2003, later translated into English in 2008 and named as The Weave of My Life A Dalit Woman's Memoirs gave her much critical acclaim and a new dimension to dalit literature.

\section{The Interview}

MS: What is your opinion about the so-called 'politics of exclusion'?

UP: The politics of exclusion in the contemporary period is a conscious issue because under the stratification of casteism, we are assumed as the Lower Castes and 'they' call themselves the Upper Castes. Yes, I admit that we are separate because of the casteist feeling. We are separate mainly because of the variation in our cultures. Their caste is different from ours in relation to [the] eating, clothing and speaking habits. Not only ours, but every culture varies with the variation in the community, class, caste, race or geographical location. But is it justified, as far as the socio-cultural norms are regarded, that a particular group of the society is thrown away to the multi-faceted excluded realms just because of the differences as mentioned above?

MS: What do you think is the major domestic issue that plays a significant role to curb independent female identity?

UP: Male domination is still prevalent in many home fronts till today in India. This has a significant connection with your first question (smiles)! This 'exclusion' is at the domestic level, typical to the women. This form of exclusion starts when a woman wishes to educate herself. When she starts visiting the library or takes part in public debates and forums, which is not quickly expected by the patriarch of the house. He expects her to stay at home and just do the household chores, like taking care of the children etc, which is the general traditional ideology.

MS: This is the general issue offemale 'exclusion' at home. What is Dalit special in this regard?

UP: Dalit women have an added sense of exclusion on the basis of economical standard. The caste hierarchy renders Dalit women poor. A Dalit woman generally doesn't have her bank balance or rich jewelleries. Further, she has no strong backing behind her, so that she could rely on or feel confident for. That's why the husband starts suppressing her and her internal wishes. She is forced to live a confined life where she finds no scope for educating herself. 
MS: You said that Dalit women are forced to stay confined to the household duties, but in your autobiography you have mentioned that your mother used to weave aaydans (bamboo baskets) to supplement the family income...

UP: Yes, they are secluded, but as far as acquisition of education and experiences related to it, is concerned! No Dalit man prevents his wife to stay away from work, as far as earning is concerned, as it adds to the family income which is the dire need at home. As for my mother, she had to face hardships after my father passed away at an early age. He was a school teacher, but when I was in standard III he passed away, leaving the kids in a tender age. Meeting the [household] expenses was very difficult, and in those days my mother received no pension, though she got it later. When my father was alive, he always used to insist my mother to pay emphasis upon our education. Therefore, even after his death she was very particular about our education, so in order to make the ends meet she used to weave more ferociously [furiously] than before.

MS: What difference do you find in the service strategies of women belonging to the savarna society with that of yours?

UP: It's a good question! As I have pointed out in [my answer to] your previous question that no Dalit man stops his woman from working outside because it's a common trend among Dalits. But among the upper castes, usually men feel that being in the higher strata of the society, how could they let their women go out for work! Let them stay at home! They have the attitude, "We would work outside and our women would sit and eat". This attitude is absent among Dalit men.

MS: According to your autobiography The Weave of My Life, there were problems and tensions at home, as far as your going out was concerned. Why did this problem arise?

UP: There was no problem as far as my going out for service was concerned. My husband allowed me to work in the office, as I added to the family income. After that I was expected to take care of the household duties. That was all he wanted! But my wishes were quite different. I thought life doesn't mean this much. I wanted to learn more, I knew I could write, so I was determined to write. From here our vision [of life] started changing.

\section{MS: Later you became a radical activist. How did it help to mould your ideas further?}

UP: You know what! This issue is something that should be perceived through the heart. If you see things just through your eyes, you won't be able to take the right approach. I found this right approach by perceiving things through the heart. And that's through the Ambedkarite ideologies. After I got the knowledge as to how to perceive things through the heart, I could then understand how to think towards one's progress. For me jati is just like the five fingers of our hand, if one of our fingers is wounded, then we feel the pain only there, the other fingers don't understand the pain caused there! Our caste system is just the same, we are wounded, hence we could only feel and understand the pain. With this wounded identity, we use our hearts to see things. We could well understand how others see us, from the body language of the people especially.

MS: You have quite often mentioned that education also helps raise self-consciousness to a great extent. To what extent does education help to see things clearly, especially for a Dalit?

UP: Education is a big boon to Dalits if only they could use it the right away! It certainly makes us aware of quite a number of issues of which we were ignorant. I don't mean that illiterates are not aware. Jati related awareness is everywhere. But if we are educated, our perception towards this jati consciousness becomes prominently clear in us. We then become very conscious about ourselves, like our style of living, our dressing etc. But when it comes to social behaviour, the 
upper caste gets a chair to sit and we are asked to sit on the floor (disturbed)! From these small gestures, we become completely aware of their attitude towards us. I hope education would again bring equality so that we get a dignified position beside them!

MS: How far did the wish to assert your Dalit identity on the public platform disturb the domestic ambience?

UP: The problem started when I wanted to write. My husband didn't understand much about all this! He said, "Why do you write?" and "What's the use?" he used to say, "If you want to write then stay at home and write!" I don't mean he was bad. He wasn't too harsh; he never went extremely violent towards me. Sometimes he used to land two-three fists on me, (grins) he never used to beat me black and blue!

MS: When your name got changed after marriage (as is the tradition in many homes), did you feel a loss of your real identity? As name is the biggest identity of an individual.

UP: During the initial days of my marriage, I was ignorant about all these identity issues. Moreover, to be honest I didn't like my previous name, 'Vimal'. Vimal, Kamal...sound so stereotypical! (smiles) So I had a wish that after my marriage I would change my name. I planned to name myself Urmila. I liked it mainly because it has a mythological reference. In the Ramayana, Sita accompanied her husband Ram to the exile, but Urmila stayed behind to serve her in-laws, it was a big sacrifice on the part of Urmila.

MS: When you changed your name, was there any pressure from the side of your in-laws in giving the name chosen by you?

UP: My in-law's place was different from other Dalit families. My husband was educated, so was I! No one could say anything on the face of an educated person. I got this freedom just because of being educated. Besides, let me tell you something! (In a lighter mood) My mother-in -law believed that when her son's name is Harishchandra, his wife should be named Taramati automatically! When my mother-in-law announced my name to be Taramati, I gave a meaningful glance to my husband! He knew what I wanted to be named...poor fellow (laughs). He immediately denied and said it should be Urmila! Accordingly my named was finalized as Urmila.

MS: In your autobiography, you have talked about multifaceted pain that you have undergone, as a Dalit gendered individual. Which incident left the deepest mark on your mind?

UP: This question shouldn't be answered! (keeps silent for sometime) That's something extremely personal. (becomes extremely serious, losing the usual humor) No mother can forget the loss of her son. That's very painful! Please proceed with the next question.

MS: Did it affect your children in any way?

UP: No, that didn't affect the kids but I must tell you another problem relating to the kids! The problem then was Dalits had narrow outlook due to the caste discriminations. We had never witnessed the broad, limitless sky! We didn't know the world that exists outside. Had no idea about moving ahead in life. We had no issue about our relatives staying abroad! Our life was limited. The same narrow outlook of ours had an adverse effect on our kids. We sent our kids to the municipal schools. Our kids performed better than others because the other kids at school had come from the slums, whereas our kids were from educated parents and lived in better colonies. We felt happy to see that our kids are doing well. Also we used to hear from the politicians saying [things] against the English language learning system. They used to assert that English is not our language, amchi Marathi (our Marathi), we should be proud of it! Accordingly 
we sent our kids to the Marathi schools. However, later there were great social changes. After our kids' schooling, when they went to colleges, then English became a great hurdle! When the professors in the college, taught in English then they couldn't follow properly. They came home and blamed us as to why did we send them to the Marathi school? Why couldn't we send them to the English medium schools despite the two earning members at home to support the family? But the fact is, we were completely naïve towards [ignorant about] this issue!

\section{MS: How would you generalize this problem with the Dalits?}

UP: This is the general problem with the Dalits. We have no perception about this matter. Even in the slums, the Dalits have no idea about the benefits of education; they don't know the strength of this weapon which could tackle the world efficiently. Hence, they are [lagging] behind. I should thank the government for providing scholarships, free meals etc to encourage education, still they don't send their kids to school. This is due to the lack of awareness. When they would achieve awareness, the confidence to move ahead would simultaneously follow.

MS: You and I have something similar with each other. You are a Dalit woman and me, a Muslim. In many respect Muslims are also considered as Dalits. How far do you agree with this view?

UP: Yes, you are right, to a large extent we are same. But your tradition and laws are quite different and sometimes it's rigid. Undoubtedly you too have hierarchy as far as your society is concerned. You too have high and low feeling! Consider for example, the Ansaris and the Patels. This is the class stratification that you find. Though, you have never suffered untouchability like us in the strict terms.

\section{MS: But what is typical regarding the feminist issue in both the cases?}

UP: That's what I'm trying to say. See, this hierarchy provides unequal distribution of benefits to the people of both the societies. If your husband is a Patel, a rich landlord, you are ultimately going to enjoy his wealth! Are you going to dwell in the slums and he in his palatial house? No! Obviously you will stay with him. But the woman in the lower economic position would be deprived of what you enjoy. So, the class inevitably matters irrespective of religion. But as far as patriarchal domination is concerned, Muslims have a different dimension to it! When your law insists you to follow the parda system strictly or many other such laws, then it depends on you and your husband, how strictly you follow it. If your husband is liberal, you would enjoy the liberty but if your husband persists with the burkha, you would have to follow him even if you don't prefer, you have no way! Thus, sometimes under the guise of religion men try to dominate their women at different levels and patriarchy inevitably has its strong hold.

MS: How can you link the Dalit feminist issue to all the feminist issues in general?

UP: The common link is that as far [long] as men have their muscularity (within themselves) and women have their femininity, they would always go parallel. None of us could go out alone at night! Can we?

*The abbreviations used in this interview are the initials of Urmila Pawar (UP) and Munira Salim (MS). 